\title{
Appendicolith: an explicit factor leading to complicated appendicitis in childhood
}

\author{
Ning Wang, M.D. ${ }^{a, b}$, Xiaodong Lin, BS. ${ }^{c}$, Shanshan Zhang, M.S. ${ }^{a, b}$, Wei Shen, M.S. ${ }^{a, b}$ \\ and Xuedong $W u, M . D .{ }^{a, b}$
}

\begin{abstract}
Objectives. This study aims to assess the clinical risk of pediatric appendicitis with appendicolith and its guiding significance in therapeutic strategies' selection.

Methods. Children diagnosed with acute appendicitis from June 2011-January 2017 were analyzed retrospectively. Patient cohort was divided to appendicolith group (AG) and nonappendicolith group (NAG) based on whether the appendicolith presents or not in the open surgery. Clinical presentations, laboratory parameters, computed tomography findings, and pathological changes were reviewed and compared between two groups.

Results. Among 163 patients, 23 (mean age, 6.1 years old) were defined in AG and 140; mean age, 8.1 years old) in NAG. The patients in AG demonstrated prolonged length of stay (12.4 $\pm 5.6 \mathrm{~d}$ vs. $8.7 \pm 5.0 \mathrm{~d}, \mathrm{P}<0.05)$, higher body temperature $\left(38.2 \pm 0.8^{\circ} \mathrm{C}\right.$ vs. $\left.37.3 \pm 0.8^{\circ} \mathrm{C}, \mathrm{P}<0.05\right)$, higher frequency of diarrhea (17\% vs. $3 \%, \mathrm{P}$ $<0.05)$, rebound tenderness (100\% vs. $87 \%$, P $<0.05)$, increased neutrophil percentage $(81.4 \pm 8.0$ $\%$ vs. $65.3 \pm 22.8 \%, \mathrm{P}<0.05)$, C-reactive protein (33.13 $\pm 10.3 \mathrm{mg} / \mathrm{L}$ vs. $23.7 \pm 13.7 \mathrm{mg} / \mathrm{L}, \mathrm{P}<0.05)$, and great risk of perforation (78 \% vs. $29 \%, \mathrm{P}$ $<0.05)$. Alvarado score $(8.3 \pm 1.2$ vs. $7.0 \pm 1.3, \mathrm{P}$ $<0.05)$ and AIR score $(10.7 \pm 1.6$ vs. $7.7 \pm 1.9, \mathrm{P}$ $<0.05)$ of AG, were higher than NAG he presence of fever and appendicolith was associated with a high rate of perforated appendicitis.

Conclusions. Pediatric appendicitis with appendicolith has greater clinical risk and tends to causing complicated appendicitis.

Key words: appendicoliths, child, appendicitis, inflammation.
\end{abstract}

http:/ / dx.doi.org/10.5546/ aap.2020.eng.102

To cite: Wang N, Lin $X$, Zhang S, Shen $\mathrm{W}, \mathrm{Wu}$ $X$. Appendicolith: an explicit factor leading to complicated appendicitis in childhood. Arch Argent Pediatr 2020;118(2):102-108.

Funding:

The authors received financial support from Scientific Research Fund of Dali University (KYBS2018017).

Conflict of interest:

None.

Received: 3-1-2019

Accepted: 9-5-2019

\section{INTRODUCTION}

Acute appendicitis accounts for the principal parts of pediatric surgical emergencies. ${ }^{1,2}$ Appendectomy is a classical method to treat the appendicitis. Non-operative method seems to be effective in management of acute uncomplicated appendicitis. ${ }^{3-7}$ Accurate selection of patients whose appendix inflammation could be controlled by the use of antibiotics may improve the success rate of nonsurgical treatment.

Appendicolith is a definite obstructive factor to cause appendix inflammation, which can be easily detected by abdominal computed tomography (CT) scan. The clinical significance of an appendicolith discovered by CT scan and selection of treating strategy in appendicitis with appendicolith remains controversial. The presence of appendicolith is associated with earlier and higher rates of appendiceal perforation in patients with acute appendicitis. ${ }^{8}$ However, Khan MS et al., considered some patients with incidentally discovered appendicolith did not develop appendicitis. ${ }^{2}$ Rabinowitz $\mathrm{CB}$ et al., found that appendicolith may be a higher risk for appendicitis but is not an indication for appendectomy. ${ }^{9}$ The risk and degree of appendiceal inflammation initiated by an appendicolith need to be further elucidated. Appropriate clinical decision-making for management of appendicitis with appendicolith remains unclear.

The present study aims to evaluate clinical risk and degree of inflammation in pediatric appendicitis caused by appendicolith. We presume pediatric appendicitis with appendicolith has higher clinical risk 
and more serious inflammatory reaction than patients without appendicolith.

\section{POPULATION AND METHODS Patient populations}

The study obeys medical ethics standards and was subjected to approved by Medical Ethics Committee of the First Affiliated Hospital, Dali University. We found 257 children diagnosed with acute appendicitis from June 2011 to January 2017 in our pediatric surgery institution. The exclusion criterion of patients was as follows: antibiotic application outside of hospital, patients' legal guardian refusing invasive procedures and selecting antibiotic therapy, impacted stool in the appendix, oncology patients, the absence of a CT scan of the abdomen, and children undergoing treatment with systemic corticoid. Children who underwent open surgery were included in the present study. Based on the operative findings, one group was defined as fecalithrelated appendicitis (appendicolith group) and another was confirmed as non-fecalith-related appendicitis (non-appendicolith group).

\section{Clinical data}

A surgical resident reviewed and collected the medical records of the patients. The clinical data of each patient were recorded as following: demographic data, symptoms (including fever, vomiting, anorexia, migrate pain, diarrhea), signs (as body temperature, Mac Burney sign, muscle guarding, and rebound tenderness), laboratory parameters consisted with white blood cells counts $\left(\times 10^{9} / \mathrm{L}\right)$, neutrophil percentage $(\%)$, red blood cells counts $\left(\times 10^{9} / \mathrm{L}\right)$, hemoglobin $(\mathrm{g} / \mathrm{L})$, blood amylase (IU/L), C-reactive protein ( $\mathrm{mg} / \mathrm{L}$ ), serum sodium concentration $(\mathrm{mmol} / \mathrm{L})$, serum potassium concentration $(\mathrm{mmol} / \mathrm{L})$. Operative findings, including whether appendicolith present or not and general changes of appendix, also were collected based on the operation note.

\section{Clinical risk score}

Alvarado score and appendicitis inflammatory response score (AIR) were used to evaluate clinical risk of pediatric appendicitis with or without appendicolith. A physician blinded to the patient final diagnosis scored every patient according to the detailed scoring rules based on children's symptoms, signs, and laboratory tests. The aggregate score of Alvarado system is 12, and for AIR is 10 (see Table 1). According to individual Alvarado score, patients were stratified in three risk levels: low risk (score: 1-4), intermediate risk (score: 5-6), and high risk (score: 7-10).

\section{Radiological examinations and analyses}

Parents were informed about the need and radiological damage of CT scan to children. They agreed to the child to receive abdominal unenhanced CT scan. The Philips Brilliance 64-MDCT system was utilized for scanning from diaphragmatic domes to the pubic symphysis with patients in a supine position. Imaging parameters were: slice thickness $(3 \mathrm{~mm})$, tube

TABLE 1. Components of Alvarado score and appendicitis inflammatory response score

\begin{tabular}{|c|c|c|}
\hline Clinical criterion & Alvarado score & AIR score \\
\hline \multicolumn{3}{|l|}{ Symptoms } \\
\hline Nausea or vomiting & 1 & 1 \\
\hline Anorexia & 1 & \\
\hline Migration of pain to the right lower quadrant & 1 & \\
\hline \multicolumn{3}{|l|}{ Signs } \\
\hline Pain in right lower quadrant & 2 & 1 \\
\hline Rebound tenderness or muscular defense & 1 & \\
\hline Light & & 1 \\
\hline Medium & & 2 \\
\hline Strong & & 3 \\
\hline Body temperature $>37.5^{\circ} \mathrm{C}$ & 1 & \\
\hline Body temperature $>38.5^{\circ} \mathrm{C}$ & & 1 \\
\hline \multicolumn{3}{|l|}{ Laboratory tests } \\
\hline Leukocytosis & 2 & 2 \\
\hline Neutrophilia $>75 \%$ & 1 & 1 \\
\hline \multicolumn{3}{|l|}{ C-reactive protein concentration } \\
\hline $10-49 \mathrm{~g} / \mathrm{L}$ & & 1 \\
\hline$\geq 50 \mathrm{~g} / \mathrm{L}$ & & 2 \\
\hline Total score & 10 & 12 \\
\hline
\end{tabular}

AIR: appendicitis inflammatory response. 
voltage $(120 \mathrm{KV})$, and maximum tube current (250mA).

A radiologist was blinded with the clinical information on each patient and reviewed the imaging film on a PACS workstation system. He assessed $3 \mathrm{~mm}$ thick slice in axial and coronal CT images to determine the presence of appendicolith as the following features: round or regular shape, high attenuation, and diameters larger than $2 \mathrm{~mm}$ substances in the appendix.

\section{Pathological evaluations}

Excised appendectomy specimens were fixed in $10 \%$ formaldehyde solution, and tissues were embedded in paraffin; $10 \mu \mathrm{m}$ slices were made and stained with hematoxylin-eosin. A pathologist made a final diagnosis under microscopy, including simple, suppurative, and gangrenous appendicitis, based on the degree of appendiceal inflammation.

\section{Statistical analyses}

SPSS software (IBM SPSS Statistics-version 22) was used to statistical analysis. Categorical data were compared with the chi-squared test, and measurement's data were compared with the independent $t$-test. Continuous data were shown as means ( \pm standard deviations). Binary logistic regression was used to calculate odds ratios (ORs) of perforated appendicitis, depending on the clinical presentations, laboratory tests, and the presence of appendicolith. P values of $<0.05$ were considered statistically significant.

\section{RESULTS}

\section{Clinical findings}

One hundred sixty-three children (male 84 and female 79 , mean age $7.7 \pm 3.5$ years old) with the pathological diagnosis of acute appendicitis were enrolled in this study. Appendicolith-related appendicitis was found in 23 patients (14.1\%) and non-appendicolith related appendicitis in $140(85.8 \%)$. No obvious sex predominance was observed between two groups. All of the children have similar onset time $(\mathrm{p}=0.489)$, but patients in appendicolith group have longer length of stay $(p=0.001)$. Except for high frequency of diarrhea in appendicolith group $(p=0.03)$, the occurrence of other symptoms had no significant differences. Children in appendicolith group have increased neutrophil percentage $(p=0.001)$, greater level of $C$-reactive protein $(p=0.002)$, and higher serum sodium concentration $(\mathrm{p}<0.001)$. The rest of laboratory tests were not shown significant differences. Among 23 appendicolith-related appendicitis, the presence of appendicolith in abdominal CT scans before surgery was discovered in $19(83 \%)$ patients, and $4(17 \%)$ were found in operation (see Table 2).

\section{Clinical risk scores}

We evaluate the clinical risk of appendicitis in two separate groups using Alvarado score and appendicitis inflammatory response score (AIR). Alvarado and AIR score of appendicolith group were higher than non-appendicoliths group $(\mathrm{p}<0.001)$. Most patients in appendicolith group distributed in higher scoring range of Alvarado or AIR score, but the majority of patients in nonappendicoliths group distributed in middle scoring range (see Figure 1). In appendicolith group, none of the children were defined as low risk $(\mathrm{p}=0.564)$, and the majority had a high risk $(\mathrm{p}=0.004)$ (see Table 3$)$.

\section{Pathological changes}

Both of hyperemia and edema were the most frequent changes of appendix in each patient. Patients in appendicolith group had a higher incidence of pus $(p<0.001)$, perforation $(p<0.001)$, and abdominal or pelvic abscess $(\mathrm{p}=0.004)$. The dominant histological changes in nonappendicolith group were simple $(\mathrm{p}=0.001)$ and suppurative appendicitis $(\mathrm{p}=0.043)$. The incidence of gangrenous appendicitis was $29 \%$ in patients without appendicolith. None of the children in appendicolith group was diagnosed as simple appendicitis, and the majority of cases were defined to have gangrenous changes $(\mathrm{P}<0.001)$ (see Table 4).

\section{Risk factors related to perforated appendicitis}

The proportion of perforated appendicitis in 163 children was $36 \%$ (59/163). Appendicolith group showed a higher rate of perforation than non-appendicolith group ( $\mathrm{p}<0.001$ ). We choose meaningful variables of clinical findings between two groups and calculate odds ratios (ORs) of perforated appendicitis depending on the clinical presentations, laboratory tests, and the presence of appendicolith. Among multiple variables, only fever $(p=0.001)$ and the presence of appendicolith $(p=0.009)$ were associated with perforated appendicitis (see Table 5).

\section{DISCUSSION}

Appendicolith, a specific factor detected by radiography in patients presenting with 
abdominal pain, ${ }^{10}$ can be used as a predictor of acute appendicitis. ${ }^{11}$ In our study, the incidence rate of pediatric appendicitis with appendicolith is $14.1 \%$ and $83 \%$ of these patients were detected by $\mathrm{CT}$ scan before operation. It further verifies $\mathrm{CT}$ scan is an efficient method to find appendicolith in pediatric appendicitis. Notably, $17 \%$ of appendicolith were unable to be detected by CT examination. Previous studies reported the prevalence of appendicolith in pediatric appendicitis has reached at $50 \% .^{12}$ Distinctive differences in the incidence rate of pediatric appendicitis with appendicolith may be due to diverse study population. Additionally, we just included patients diagnosed during surgery. It eliminates potential interference caused by false-positive or false-negative findings of CT scan. Twenty-three pediatric appendicitis with appendicolith we included have a good representation in further analyses. Based on the

TABLE 2. Demographic, clinical and laboratory parameters between appendicoliths and non-appendicoliths groups in children with appendicitis

\begin{tabular}{|c|c|c|c|}
\hline Clinical information & Appendicoliths group $(n=23)$ & Non-appendicoliths group $(n=140)$ & $p$ value ${ }^{*}$ \\
\hline Age (mean, SD) & $6.1 \pm 3.1$ & $8.1 \pm 3.6$ & \\
\hline \multicolumn{4}{|l|}{ Sex } \\
\hline Male & $9(39 \%)$ & $75(54 \%)$ & \\
\hline Female & $14(61 \%)$ & $65(46 \%)$ & \\
\hline Onset time $(\mathrm{h})$ & $50.3 \pm 30.1$ & $56.2 \pm 39.0$ & 0.489 \\
\hline Length of stay (d) & $12.4 \pm 5.6$ & $8.7 \pm 5.0$ & $0.001^{*}$ \\
\hline \multicolumn{4}{|l|}{ Symptoms } \\
\hline Fever $\left(>37.7^{\circ} \mathrm{C}\right)$ & $11(48 \%)$ & $40(29 \%)$ & 0.065 \\
\hline Vomiting & $3(13 \%)$ & $45(32 \%)$ & 0.063 \\
\hline Anorexia & $9(39 \%)$ & $45(32 \%)$ & 0.509 \\
\hline Migration pain & $3(13 \%)$ & $22(16 \%)$ & 0.742 \\
\hline Diarrhea & $4(17 \%)$ & $4(3 \%)$ & $0.03^{*}$ \\
\hline \multicolumn{4}{|l|}{ Signs } \\
\hline Body temperature $\left({ }^{\circ} \mathrm{C}\right)$ & $38.2 \pm 0.8$ & $37.3 \pm 0.8$ & $<0.001^{*}$ \\
\hline Mac Burney sign & $23(100 \%)$ & $140(100 \%)$ & \\
\hline Muscular defense & $5(22 \%)$ & $15(11 \%)$ & 0.104 \\
\hline Rebound tenderness & $23(100 \%)$ & $122(87 \%)$ & $0.03^{*}$ \\
\hline \multicolumn{4}{|l|}{ Laboratory tests } \\
\hline White blood cells count $\left(\times 10^{9} / \mathrm{L}\right)$ & $15.7 \pm 5.3$ & $13.1 \pm 5.8$ & 0.43 \\
\hline Neutrophil percentage $(\%)$ & $81.4 \pm 8.0$ & $65.3 \pm 22.8$ & $0.001^{*}$ \\
\hline Red blood cells count $\left(\times 10^{9} / \mathrm{L}\right)$ & $4.5 \pm 0.4$ & $4.7 \pm 0.5$ & 0.063 \\
\hline Hemoglobin (g/L) & $131.6 \pm 14.9$ & $136.4 \pm 14.0$ & 0.133 \\
\hline Blood amylase (IU) & $59.5 \pm 17.5$ & $60.2 \pm 20.0$ & 0.873 \\
\hline C-reactive protein $(\mathrm{mg} / \mathrm{L})$ & $33.13 \pm 10.3$ & $23.69 \pm 13.7$ & $0.002^{*}$ \\
\hline$[\mathrm{K}+](\mathrm{mmol} / \mathrm{L})$ & $4.1 \pm 0.5$ & $4.2 \pm 0.4$ & 0.521 \\
\hline$[\mathrm{Na}+](\mathrm{mmol} / \mathrm{L})$ & $135.0 \pm 3.9$ & $139.1 \pm 5.0$ & $<0.001^{*}$ \\
\hline \multicolumn{4}{|l|}{ CT scan } \\
\hline Calcified point at right & $19(83 \%)$ & $0(0)$ & $<0.001^{*}$ \\
\hline
\end{tabular}

$\left[\mathrm{K}^{+}\right]$: serum potassium concentration, $\left[\mathrm{Na}^{+}\right]$: serum sodium concentration, IU: international unit, CT: computed tomography. Categorical data are indicated as number of patients (percentage, \%). Measurement data are indicated by mean \pm standard deviation. *p value $<0.05$ statistical significance.

FIGURE 1. Distribution diagrams of Alvarado and AIR score between appendicoliths and non-appendicoliths group
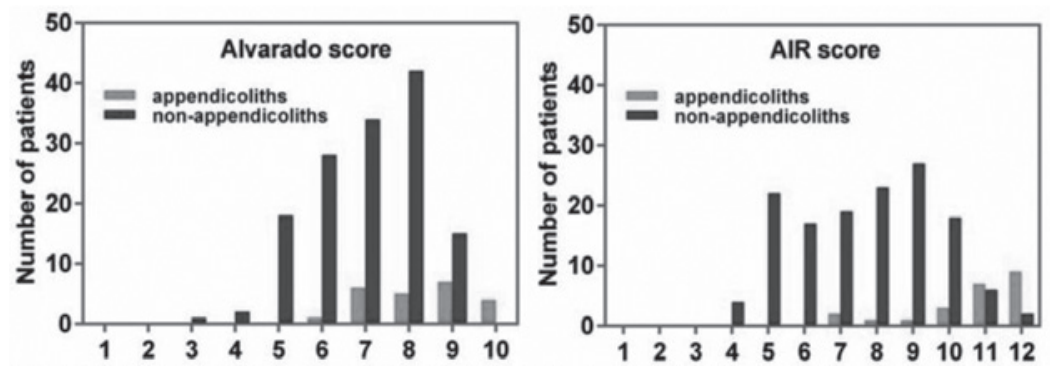
results from the retrospective and comparative study in 163 pediatric patients, pediatric appendicolith-related appendicitis presented with longer length of stay, higher frequency of diarrhea, more serious inflammatory reaction, and higher perforation rate than those patients without appendicolith.

Non-operative management using antibiotics to treat pediatric uncomplicated appendicitis may be feasible and effective. However, the presence of appendicolith in the uncomplicated appendicitis decreased the success rate of antibiotic therapy. ${ }^{13}$ It indicates the existence of appendicolith may lead to antibiotics uncontrollable inflammatory reaction in appendix. Previous study presented the efficacy of non-operative management to treat pediatric appendicitis with an appendicolith, ${ }^{14}$ but, higher recurrence of appendicitis after treating by non-operative management was also reported. ${ }^{8}$ The efficacy of non-surgical management may be limited due to potential risk of appendiceal perforation in patients with appendicolith. In the present study, the rate of perforation in 140 pediatric appendicitis without appendicolith is $29 \%$, but $78 \%$ in 23 appendicolith-related appendicitis. Increased risk of appendiceal perforation in pediatric appendicitis with appendicolith raises

TABLE 3. Clinical risk scoring of appendicoliths and non-appendicoliths groups for suspected acute appendicitis

\begin{tabular}{lccc}
\hline Clinical risk scoring & $\begin{array}{c}\text { Appendicoliths } \\
\text { group (n=23) }\end{array}$ & $\begin{array}{c}\text { Non-appendicoliths } \\
\text { group (n=140) }\end{array}$ & $p$ value $^{*}$ \\
\hline Alvarado score & $8.3 \pm 1.2$ & $7.0 \pm 1.3$ & $<0.001^{* *}$ \\
AIR score & $10.7 \pm 1.6$ & $7.7 \pm 1.9$ & $<0.001^{*}$ \\
Risk & $0(0)$ & $2(1 \%)$ & 0.564 \\
$\quad$ Low & $1(4 \%)$ & $46(33 \%)$ & $0.005^{*}$ \\
Intermediate & $22(96 \%)$ & $92(66 \%)$ & $0.004^{* *}$ \\
High & & & \\
\hline
\end{tabular}

AIR: Appendicitis inflammatory response.

Low risk: Alvarado score 1-4; intermediate risk: Alvarado score 5-6; high risk: Alvarado score 7-10 (17).

Categorical data are indicated as number of patients (percentage, \%). Measurement data are indicated by mean \pm standard deviation. *p value $<0.05$ statistical significance.

TABLE 4. Contrastive analysis of pathological changes between appendicoliths and non-appendicoliths groups in children with appendicitis

\begin{tabular}{lccc}
\hline Pathological changes & $\begin{array}{c}\text { Appendicoliths } \\
\text { group (n=23) }\end{array}$ & $\begin{array}{c}\text { Non-appendicoliths } \\
\text { group (n=140) }\end{array}$ & $p$ value $^{*}$ \\
\hline General changes & $23(100 \%)$ & $140(100 \%)$ & 0.24 \\
$\quad$ Hyperemia & $23(100 \%)$ & $132(94 \%)$ & $<0.001^{*}$ \\
Edema & $21(91 \%)$ & $57(41 \%)$ & $<0.001^{*}$ \\
Pus & $18(78 \%)$ & $41(29 \%)$ & $0.004^{*}$ \\
Perforation & $7(30 \%)$ & $13(9 \%)$ & $0.001^{*}$ \\
Abdominal or pelvic abscess & & $45(32 \%)$ & $0.043^{*}$ \\
Microscopic findings & $0(0)$ & $55(39 \%)$ & $<0.001^{*}$ \\
Simple & $4(17 \%)$ & $40(29 \%)$ & \\
Suppurative & $19(83 \%)$ & & \\
Gangrenous & &
\end{tabular}

Categorical data are indicated as number of patients (percentage, $\%$ ). ${ }^{*} \mathrm{p}$ value $<0.05$ statistical significance.

TABLE 5. Multivariate analysis by means of logistic regression

\begin{tabular}{lcc}
\hline Variables & OR $\mathbf{( 9 5} \% \mathbf{C I})$ & $\boldsymbol{P}$ value \\
\hline Fever & $3.156(1.587-6.273)$ & $0.001^{*}$ \\
Diarrhea & $0.268(0.042-1.719)$ & 0.165 \\
Rebound tenderness & $1.382(0.456-4.184)$ & 0.568 \\
C-reactive protein (mg/L) & $1.009(0.981-1.037)$ & 0.540 \\
Neutrophil percentage (\%) & $0.994(0.977-1.011)$ & 0.472 \\
Appendicolith & $5.730(1.556-21.107)$ & $0.009^{*}$ \\
\hline
\end{tabular}


the question that whether or not pediatric appendicitis with appendicolith can be treated with non-surgical management. Additionally, clinical features of pediatric appendicitis caused by appendicolith have not been well established, as well as the degree of appendiceal inflammation. If the features of appendiceal inflammation and the risk of perforation in pediatric appendicitis with appendicolith could be well elucidated, we will be able to make an appropriate strategic choice between surgical and non-surgical management.

Several scoring systems have been applied to evaluate the clinical risk of acute appendicitis, which can reflect the extent of inflammatory reaction of the suspected appendicitis. The most commonly used system is Alvarado score. Recently, the appendicitis inflammatory response score (AIR) has been developed and seems to surpass the Alvarado score in terms of accuracy. ${ }^{15}$ Both of Alvarado score and AIR were used to reevaluate the clinical risk of the groups of patients under examination. Indeed, with similar onset time, patients getting appendicolith-related appendicitis have significantly higher clinical risk. The major pathological change of the appendix in patients with appendicolith is gangrenous appendicitis on the basis of pathological investigations of resected appendix, which is the presentation of progressive inflammation. It shows that the emergence of appendicolith in the appendix is a factor to cause the enhanced inflammatory response significantly increasing the clinical risk of affected patients.

Clinical significance of appendicolith incidentally discovered in patients without the presentations of appendicitis remains controversial. On one hand, existing clinical evidence demonstrates that the presence of fecalith in the appendix lumen is an explicit mechanically obstructive factor related to appendicitis. The incidence of an isolated appendicoliths with associated CT signs of appendicitis was $97.4 \% .{ }^{16}$ Larger size fecalith located at the base of appendix was associated with complicated appendicitis. ${ }^{12}$ It may be reasonable to presume that the emergence of appendicolith could be a high risk factor of appendicitis. On the other hand, appendicoliths detected by CT scan without inflammatory signs may be transient without special clinical importance. ${ }^{2,16} \mathrm{An}$ appendicolith also can be found in $20 \%$ children who undergone appendectomy for suspected appendicitis without pathological features of appendicitis. ${ }^{16}$ Indeed, a small number of patients with incidentally discovered appendicolith have not got acute appendicitis. However, longer follow-up time for such patients may be needed to evaluate the potential risk of appendicolith leading to acute appendicitis.

There are scarce reports about the clinical risk of appendicolith incidentally discovered in children without symptoms of appendicitis. On one hand, overuse of CT scanning for children without surgical indications is inappropriate due to unnecessary radiation injury. On the other hand, as an obstructive factor, the existence of appendicolith may increase the risk for appendicitis. Our study presents the clinical features of appendicolith-related appendicitis, including higher clinical risk, serious inflammatory response, and high incidence of perforation. We should pay attention to clinical significance of appendicolith identified not only in symptomatic patients but in asymptomatic patients.

Early appendectomy in asymptomatic patients with appendicolith may reduce the risk of appendicitis. More importantly, it can avoid the occurrence of complications of complicated appendicitis due to inner obstruction caused by appendicolith.

There are several limitations in our study. First, retrospective analysis of single institution can be inadequate to present the clinical picture of appendicolith-related appendicitis. A prospective study with a large number of cases from multiple centers might be better to verify the present findings. Second, all of the pediatric appendicitis with appendicolith included in this study underwent appendectomy. It cannot evaluate differences of therapeutic effects between invasive surgery and conservative treatments. In fact, patients having radiological positive findings of appendicolith were complicated with severe inflammatory response spreading to other parts of peritoneal cavity, and, surgery is more appropriate treatment for spread of abdominal infection. Finally, rare cases of asymptomatic patients with appendicolith discovered incidentally were found during our study. Involvement of appendicolith incidentally discovered in children without the presentation of appendicitis may deepen our understanding of clinical risk of appendicolith. 


\section{CONCLUSIONS}

Pediatric appendicitis with appendicolith has greater clinical risk and tends to causing complicated appendicitis. For symptomatic patients, appendicolith discovered preoperatively is an important indication for surgery aiming to control spreading abdominal infection. For asymptomatic patients, pediatrician should evaluated the clinical risk of appendicolith and make appropriate clinical decisions.

\section{REFERENCES}

1. St Peter SD, Sharp SW, Holcomb GW 3rd, Ostile DJ. An evidence-based definition for perforated appendicitis derived from a prospective randomized trial. J Pediatr Surg. 2008; 43(12):2242-5.

2. Khan MS, Chaudhry MBH, Shahzad N, Tarig M, et al. Risk of appendicitis in patients with incidentally discovered appendicoliths. J Surg Res. 2018; 221:84-7.

3. Steiner Z, Buklan G, Stackievicz R, Gutermacher M, et al. Conservative treatment in uncomplicated acute appendicitis: reassessment of practice safety. Eur J Pediatr. 2017; 176(4):521-7.

4. Vons C, Barry C, Maitre S, Pautrat K, et al. Amoxicillin plus clavulanic acid versus appendicectomy for treatment of acute uncomplicated appendicitis: an open-label, noninferiority, randomised controlled trial. Lancet. 2011; 377(9777):1573-9.

5. Ozgüç H. Appendectomy versus antibiotic treatment in acute appendicitis: a prospective multicenter randomized controlled trial. World J Surg. 2007; 31(3):615-6.

6. Bhangu A, Soreide K, Di Saverio S, Assarsson JH, Drake FT. Acute appendicitis: modern understanding of pathogenesis, diagnosis, and management. Lancet. 2015; 386(10000):1278-87.

7. Georgiou R, Eaton S, Stanton MP, Pierro A, Hall NJ. Efficacy and Safety of Nonoperative Treatment for
Acute Appendicitis: A Meta-analysis. Pediatrics. 2017; 139(3):e20163003.

8. Alaedeen DI, Cook M, Chwals WJ. Appendiceal fecalith is associated with early perforation in pediatric patients. J Pediatr Surg. 2008; 43(5):889-92.

9. Rabinowitz CB, Egglin TK, Beland MD, Mayo-Smith W. Outcomes in 74 patients with an appendicolith who did not undergo surgery: is follow-up imaging necessary? Emerg Radiol. 2007; 14(3):161-5.

10. Lowe LH, Penney MW, Scheker LE, Perez R Jr, et al. Appendicolith revealed on CT in children with suspected appendicitis: how specific is it in the diagnosis of appendicitis? AJR Am J Roentgenol. 2000; 175(4):981-4.

11. Yu CW, Juan LI, Wu MH, Shen CJ, et al. Systematic review and meta-analysis of the diagnostic accuracy of procalcitonin, C-reactive protein and white blood cell count for suspected acute appendicitis. Br J Surg. 2013; 100(3):322-9.

12. Yoon HM, Kim JH, Lee JS, Ryu JM, et al. Pediatric appendicitis with appendicolith often presents with prolonged abdominal pain and a high risk of perforation. World J Pediatr. 2018; 14(2):184-90.

13. Huang L, Yin Y, Yang L, Wang C, et al. Comparison of Antibiotic Therapy and Appendectomy for Acute Uncomplicated Appendicitis in Children: AMeta-analysis. JAMA Pediatr. 2017; 171(5):426-34.

14. Zhang HL, Bai YZ, Zhou X, Wang WL. Nonoperative management of appendiceal phlegmon or abscess with an appendicolith in children. J Gastrointest Surg. 2013; 17(4):766-70.

15. Kollár D, McCartan DP, Bourke M, Cross KS, Dowdall J. Predicting acute appendicitis? A comparison of the Alvarado score, the Appendicitis Inflammatory Response Score and clinical assessment. World J Surg. 2015;39(1):1049.

16. Rollins MD, Andolsek W, Scaife ER, Meyers RL, et al. Prophylactic appendectomy: unnecessary in children with incidental appendicoliths detected by computed tomographic scan. J Pediatr Surg. 2010; 45(12):2377-80. 